\title{
Influence of Slag Viscosity and Composition on the Inclusion Content in Steel
}

\author{
Dali YOU, Christian BERNHARD, ${ }^{*}$ Alexander MAYERHOFER and Susanne Katharina MICHELIC \\ Montanuniversität Leoben, Franz Josef Straße 18, Leoben, A-8700 Austria. \\ (Received on May 17, 2021; accepted on July 6, 2021; J-STAGE Advance published date: August 19, \\ 2021)
}

\begin{abstract}
Influence of slag viscosity and composition on the inclusion content in the steel is studied using laboratory experiments and modeling simulations. The steel samples are taken during the experimental process to record the inclusion content change. Afterwards the prepared samples are analyzed using automated scanning electron microscope and energy dispersive spectroscopy (SEM/EDS) method. A simple steel/slag reaction model is constructed based on the effective equilibrium reaction zone (EERZ) method. The inclusion content evolution process is discussed by combining the experimental and calculated results. It is found that the inclusion content evolution in the steel is determined by the inclusion generation and removal.
\end{abstract}

KEY WORDS: slag; steel; inclusion content; removal; steel/slag reaction; viscosity.

\section{Introduction}

Non-metallic inclusions in the steel may be detrimental to the mechanical properties of the final product. It is therefore desirable to minimize the inclusion content in liquid steel processing. From this sense, the top slag in the ladle treatment is essential because of its absorption function to the removed inclusions by the steel/slag interactions.

The inclusion removal to the slag involves three stages: (1) transportation to steel/slag interface; (2) separation to slag; (3) dissolution into slag. ${ }^{1-4)}$ The inclusion transportation is primarily due to the density difference between the inclusion and steel and promoted by the steel stirring. ${ }^{5)}$ Many efforts have been made to clarify the mechanism of inclusion separation. ${ }^{6-9)}$ Strandh et al. ${ }^{10,11)}$ proposed a mathematical model to study the inclusion behavior at the steel/ slag interface. It was found that the interfacial tension and slag viscosity are the most critical parameters for the inclusion separation. The positive overall wettability and low slag viscosity were believed to promote the inclusion separation. Valdez et al. ${ }^{2)}$ studied the influence of slag properties on the inclusion capture after reaching the interface using the developed models. It was suggested that the separation process was rapid enough to be ignored for the typical inclusions and slags after sensitivity analysis. Numerous studies have been performed using a confocal scanning laser microscope (CSLM) for the inclusion dissolution into slag., ${ }^{2,17}$ The dissolution process of different inclusion particles into

\footnotetext{
* Corresponding author: E-mail: christian.bernhard@unileoben.ac.at
}

ladle, tundish, and mould slags were in-situ observed. The dissolution rate was analyzed. It was generally believed that the mass transfer of the dissolved elements in the slag controls the dissolution rate. Valdez et al. ${ }^{2)}$ summarized that the inclusion dissolution time is inversely proportional to the ratio of the thermodynamic driving force $(\eta)$ and slag viscosity $(\Delta C)$ based on the measurements reported by different researchers. Michelic et al. ${ }^{17)}$ also concluded that increasing slag viscosities essentially extend the dissolution time. Lee et al. ${ }^{1)}$ observed the separation and dissolution of $\mathrm{Al}_{2} \mathrm{O}_{3}$ at the steel/slag interface. It was suggested that $\mathrm{Al}_{2} \mathrm{O}_{3}$ could pass through the interface, and the dissolution into the slag is the rate controlling step.

Additionally, there are several comprehensive studies on inclusion growth, modification and removal and the total oxygen change in the steelmaking process. ${ }^{3,18-27)}$ Reis et $a l .{ }^{3)}$ investigated the efficiency of inclusion absorption by refining slags based on the industrial experiments. They illustrated that the inclusion absorption efficiency by slag is proportional to $\Delta C / \eta$ as reported by Valdez et al. ${ }^{2)}$ Park et $\mathrm{al}^{22)}$ investigated the effects of the slag properties on the oxide removal rate by the laboratory induction furnace experiments and continuous total oxygen measurement. They confirmed that the apparent inclusion removal rate is proportional to $\Delta C / \eta$. The former studies deepen the understanding of the mechanism of inclusion removal, while it still needs further work to clarify it, e.g. the effects of steel/ slag chemical reaction and slag viscosity.

The novelty of the present work is to consider the inclusion back-transport into the steel either from the interfacial 
reaction or the slag side as one extra step of the inclusion removal besides the reported mechanism. Hence the influence of different slags on the inclusion content in the steel was investigated in Al-deoxidation experiments, using a Tammann-type furnace. The process sampling of the steel was carried out during the experiments to track the inclusion content evolution. The inclusion content in the samples was analyzed using automated scanning electron microscope and energy dispersive spectroscopy (SEM/EDS) method. A simple model was constructed based on the effective equilibrium reaction zone (EERZ) method to simulation the steel/slag reaction and inclusion content change. ${ }^{28)}$ The inclusion content evolution process was discussed by combining the experimental and calculated results. The possible mechanism of slag properties and steel/slag reaction affecting the inclusion content in the steel was proposed.

\section{Experiment}

Laboratory experiments were designed to study the influence of the slag on the inclusion in the steel. A resistance heated Tammann-type furnace Ruhrstrat HRTK32-Sond was applied to conduct the experiments under Ar-environment at $1600^{\circ} \mathrm{C}$. Due to the carbon heating tubes inside the furnace and their reaction with the residual oxygen, the final oxygen content in the furnace vessel is extremely low $(0.001 \mathrm{ppm})$. The schematic of the experimental setup is shown in Fig. 1. ${ }^{29)}$ The experimental procedure consists of the following main steps (Fig. 2):

- Approximately $300 \mathrm{~g}$ of unalloyed steel with low contents of residual elements (as listed in Table 1) was placed in an $\mathrm{Al}_{2} \mathrm{O}_{3}$ crucible. Before heating, the alumina crucible and the steel were placed in the furnace chamber, which was flushed with Argon (Ar 5.0, Argon gas with the purity of $99.999 \%$ ) for one hour to ensure a minimum of oxygen in the atmosphere.

- Heating was performed with a scheduled rate of $15^{\circ} \mathrm{C}$ $\min ^{-1}$ before $1200^{\circ} \mathrm{C}, 10^{\circ} \mathrm{C} \min ^{-1}$ between $1200^{\circ} \mathrm{C}$ to $1500^{\circ} \mathrm{C}$ and $5^{\circ} \mathrm{C} \mathrm{min}^{-1}$ from $1500^{\circ} \mathrm{C}$ to $1600^{\circ} \mathrm{C}$. After melting the iron in alumina crucibles, the melts were kept at $1600^{\circ} \mathrm{C}$ for $600 \mathrm{~s}$ to ensure proper homogenization. A sample (S0) was taken before Al-deoxidation to determine the total oxygen content before Al-killing by means of LECO combustion technique. The initial total oxygen $\left(\mathrm{O}_{\text {total }}\right)$ content is $0.031 \%$ estimated from the mass balance with considering the extra oxygen from the additions.

- The additions were added after melt homogenization at $\mathrm{t}=0$. Approximately $0.23 \mathrm{~g} \mathrm{Al}$ was first added using a protected steel tube, and then immediately $20 \mathrm{~g}$ slag was added. The mass of $\mathrm{Al}$ was defined based on the oxygen content in the steel for completed deoxidation and achieving considerable $\mathrm{Al}$ concentration. The designed slags (A and B) were pre-melted and ground into powder whose compositions and viscosities are distinct, as listed in Table 2. As shown in Fig. 2, the first sample was take at $480 \mathrm{~s}$ (S1) to ensure the slag was completely melted. The following samples were taken at $840 \mathrm{~s}$ (S2) and $2040 \mathrm{~s}$ (S3). The crucible was removed out the furnace after $4440 \mathrm{~s}$ and quenched in the water.

It is important to note that this experiment should not be considered as a simulation at the conditions in a ladle: the resistance heating of the furnace results in a most homogeneous temperature distribution inside the crucible. Only marginal temperature gradients in the melt may exist, caused by radiation. The convection in the system due to Buoyancy is negligible. The transport of the particles towards the interface steel/slag is therefore mainly controlled by Stokes forces. The particle diameter has, therefore, in this experi-

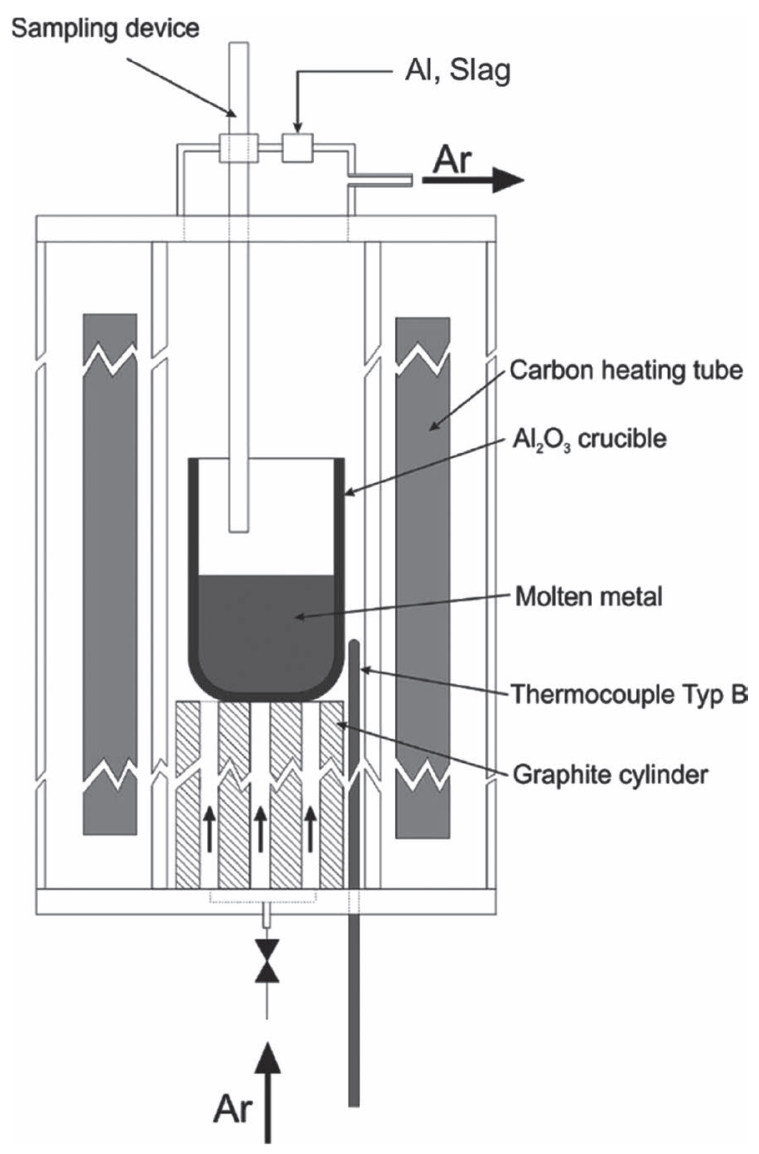

Fig. 1. Schematic illustration of the setup for Tammann Furnace experiments.

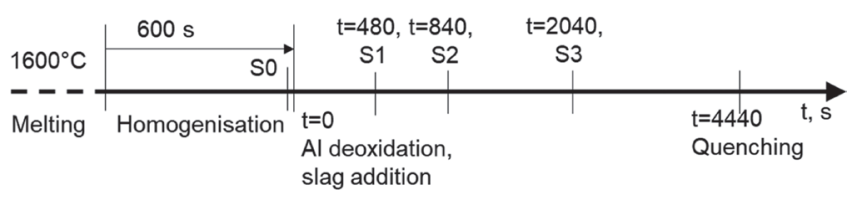

Fig. 2. Schematic of the experimental process.

Table 1. The composition of the raw steel material for the experiments (wt.\%).

\begin{tabular}{ccccc}
\hline $\mathrm{C}$ & $\mathrm{Mn}$ & $\mathrm{P}$ & $\mathrm{S}$ & $\mathrm{O}_{\text {total }}$ \\
\hline 0.0034 & 0.054 & 0.0054 & 0.0027 & 0.031 \\
\hline
\end{tabular}

Table 2. The slag compositions and additions for the experiments.

\begin{tabular}{|c|c|c|c|c|c|c|c|}
\hline \multirow{2}{*}{ Slags } & \multicolumn{3}{|c|}{$\begin{array}{l}\text { Compositions } \\
\text { (wt.\%) }\end{array}$} & \multirow{2}{*}{$\begin{array}{c}\text { Viscosity } \\
\left(1600^{\circ} \mathrm{C}, \mathrm{Pas}^{-1}\right)\end{array}$} & \multirow{2}{*}{$\begin{array}{l}\text { Mass of } \\
\text { the slag } \\
\text { (g) }\end{array}$} & \multirow{2}{*}{$\begin{array}{l}\text { Mass of } \\
\text { the steel } \\
(\mathrm{g})\end{array}$} & \multirow{2}{*}{$\begin{array}{c}\text { Mass of } \\
\text { Al } \\
\text { addition } \\
\text { (g) }\end{array}$} \\
\hline & $\mathrm{CaO}$ & $\mathrm{Al}_{2} \mathrm{O}_{3}$ & $\mathrm{SiO}_{2}$ & & & & \\
\hline A & 37 & 42 & 21 & 0.393 & \multirow{2}{*}{20} & \multirow{2}{*}{300} & \multirow{2}{*}{0.23} \\
\hline B & 28 & 51 & 21 & 0.760 & & & \\
\hline
\end{tabular}


ment a significant influence on the particle separation.

For the sampling of S0 to S3, a stainless steel tube (inner diameter $d=4 \mathrm{~mm}$; outer diameter $D=6 \mathrm{~mm}$ ) and a sucking system were applied. ${ }^{29)}$ The sampler tube was immersed into the melt to a certain depth. Liquid steel was sucked into the relatively cold tube, leading to a rapid solidification of the steel sample. Afterward, the tube was removed from the furnace and quenched in water. The time between dipping the tube into the melt and the finally quenching the sample was less than $5 \mathrm{~s}$. Thus, the formation of inclusions during cooling was suppressed and results of the automated SEM/ EDS-feature analysis were hardly influenced.

After removing the samples from the tube, their diameter was reduced from $4 \mathrm{~mm}$ to a thickness of $2 \mathrm{~mm}$ by forging. Possibly existing pores were closed. The samples were further mounted, ground, and polished for the SEM/EDS analysis. For the remaining regulus in the crucible after the experiment, the area close to the steel/slag interface was analyzed, using the same technique. The final steel compositions were also measured using classical optical spectrometry. The final steel compositions were also measured using classical optical spectrometry.

Automated particle analysis was performed by means of a JEOL 7200F field-emitting SEM equipped with an Oxford XMaxN-80 EDS-detector and Aztec analyzing software. The automated feature evaluation was performed with a magnification of 400 times and an acceleration voltage of $15 \mathrm{kV}$. A minimum of $3.5 \mathrm{~mm}^{2}$ with an ECD above $0.5 \mu \mathrm{m}$ was analyzed for each sample.

\section{Simulation}

A simple thermodynamic-kinetic model was developed to simulate the steel/slag reaction and calculate the inclusion removal rate. The schematic of the model is displayed in Fig. 3. In the model, steel, slag, and inclusion phases are considered. The steel/slag reaction is described using the EERZ method, proven to treat the interfacial reactions by different authors. ${ }^{30-33)}$ In the EERZ method, an effective equilibrium reaction zone containing both steel and slag phases (the region between the dashed lines in Fig. 3) is defined. The mass of steel $\left(\Delta m_{s t}\right)$ and slag $\left(\Delta m_{s l}\right)$ present in the interfacial reaction per time step is calculated based on the mass transfer coefficient $\left(k_{s t}\right.$ and $\left.k_{s l}\right)$, as given in Eqs. (1) and (2). The mass transfer coefficient is an adjustable parameter and is calibrated based on the measured con-

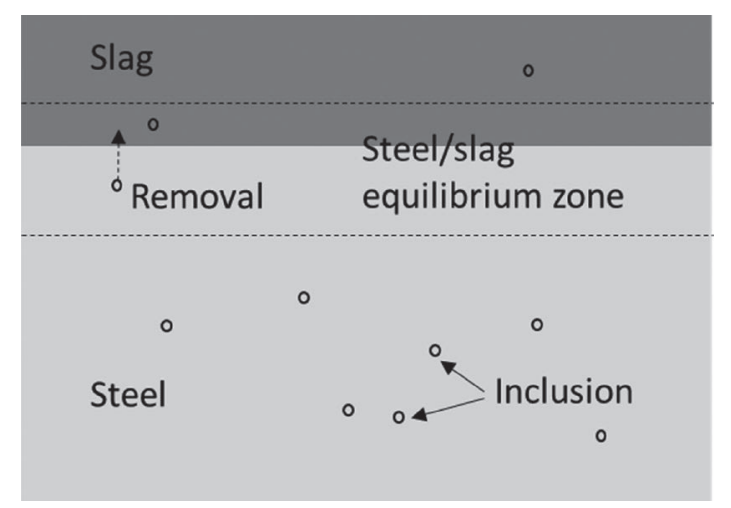

Fig. 3. Schematic of the model. centration of $\mathrm{Al}$ and $\mathrm{Si}$. The steel and slag phases return to the bulk after the interfacial reaction. There, they approach thermodynamic equilibrium, respectively. The thermodynamic library-ChemApp is applied to perform the thermodynamic equilibrium calculation. ${ }^{34)}$ The formed inclusions are assumed to be in an equilibrium state with bulk steel and removed at a time-independent, constant rate $\left(r_{r e}\right)$ to the interface. The inclusion floating rate is an adjustable parameter and parametrized by the measured inclusion content. The mass of the inclusions present in the interfacial reaction at each time step is calculated by Eq. (3). For a detailed description we refer to former publication. ${ }^{33)}$ Note that the inclusions originated from the steel/slag reaction and slag are not considered in the present model.

ChemApp links the model to the thermodynamic database of FactSage. FactSage and ChemApp are products of GTT Technologies, Herzogenrath, Germany. For the present calculations, FSstel and FToxid databases from FactSage 7.3 were applied. The LIQUID phase from FSstel is used to describe the liquid steel. The Slag-liquid phase from FToxid is applied to describe the liquid slag and liquid inclusion in the steel. Meanwhile, the following phases: $\mathrm{CaS}$ and MnS from FSstel and $\mathrm{MgO}, \mathrm{Al}_{2} \mathrm{O}_{3}, \mathrm{SiO}_{2}, \mathrm{P}_{2} \mathrm{O}_{5}, \mathrm{CaO}, \mathrm{MnO}$, $\mathrm{CaAl}_{2} \mathrm{O}_{4}, \mathrm{CaAl}_{4} \mathrm{O}_{7}$ and $\mathrm{CaAl}_{12} \mathrm{O}_{19}$ from FToxid are used to describe the precipitations in the liquid steel and slag. The input mass and compositions for the simulations are the same as listed in Tables 1 and 2. The time step is set as $20 \mathrm{~s}$.

$$
\begin{aligned}
& \Delta m_{s t}=k_{s t} A \rho_{s t} \Delta t \\
& \Delta m_{s l}=k_{s l} A \rho_{s l} \Delta t . \\
& \Delta m_{\text {incl }}=r_{r e} m_{\text {incl }} \Delta t
\end{aligned}
$$

where subscripts of $s t, s l$ and incl mean steel, slag, and inclusion in Eqs. (1) to (3), respectively; $\Delta m$ is the mass present in the interfacial reaction at each time step $\Delta t ; k$ denotes the mass transfer coefficient; $A$ is the interface area of the steel and slag; $\rho$ is the density; $r_{r e}$ is the inclusion floating rate; $m_{\text {incl }}$ is the mass of inclusions in the steel.

\section{Results and Discussion}

The measured area fraction and calculated mass percentage of different-type inclusions during the experimental process are shown in Fig. 4. As seen from Fig. 4(a), the measured inclusions include various types: $\mathrm{Al}_{2} \mathrm{O}_{3}$, $\mathrm{SiO}_{2}, \mathrm{CaO}, \mathrm{Si}-\mathrm{Ca}-\mathrm{O}, \mathrm{Mg}-\mathrm{Al}-\mathrm{O}, \mathrm{Al}-\mathrm{Ca}-\mathrm{O}, \mathrm{Al}-\mathrm{Si}-\mathrm{O}$ and 'Others'. 'Others' indicate other types of inclusions except for the aforementioned types, e.g. Al-Si-Mn-O and $\mathrm{Al}-$ $\mathrm{Si}-\mathrm{Ca}-\mathrm{Mn}-\mathrm{O}$. Not all measured inclusion types can be explained due to the complex process and various sources. In contrast, the calculated inclusions in Fig. 4(b) contain only three inclusion types: $\mathrm{Al}_{2} \mathrm{O}_{3}, \mathrm{CaAl}_{12} \mathrm{O}_{19}$ and $\mathrm{CaAl}_{4} \mathrm{O}_{7}$. The difference of the measured and inclusion types is mainly attributed to essence of the thermodynamic modeling where the inclusion collision, slag entrapment and kinetic transformation were not considered. The present work addresses the inclusion content and the composition is not dedicated.

In Fig. 4(a), from $480 \mathrm{~s}$ (S1) to 840 (S2), the total area fraction of the inclusions changes little in both samples with slags $\mathrm{A}$ and $\mathrm{B}$. The $\mathrm{Al}_{2} \mathrm{O}_{3}$ remains the dominant inclusion 

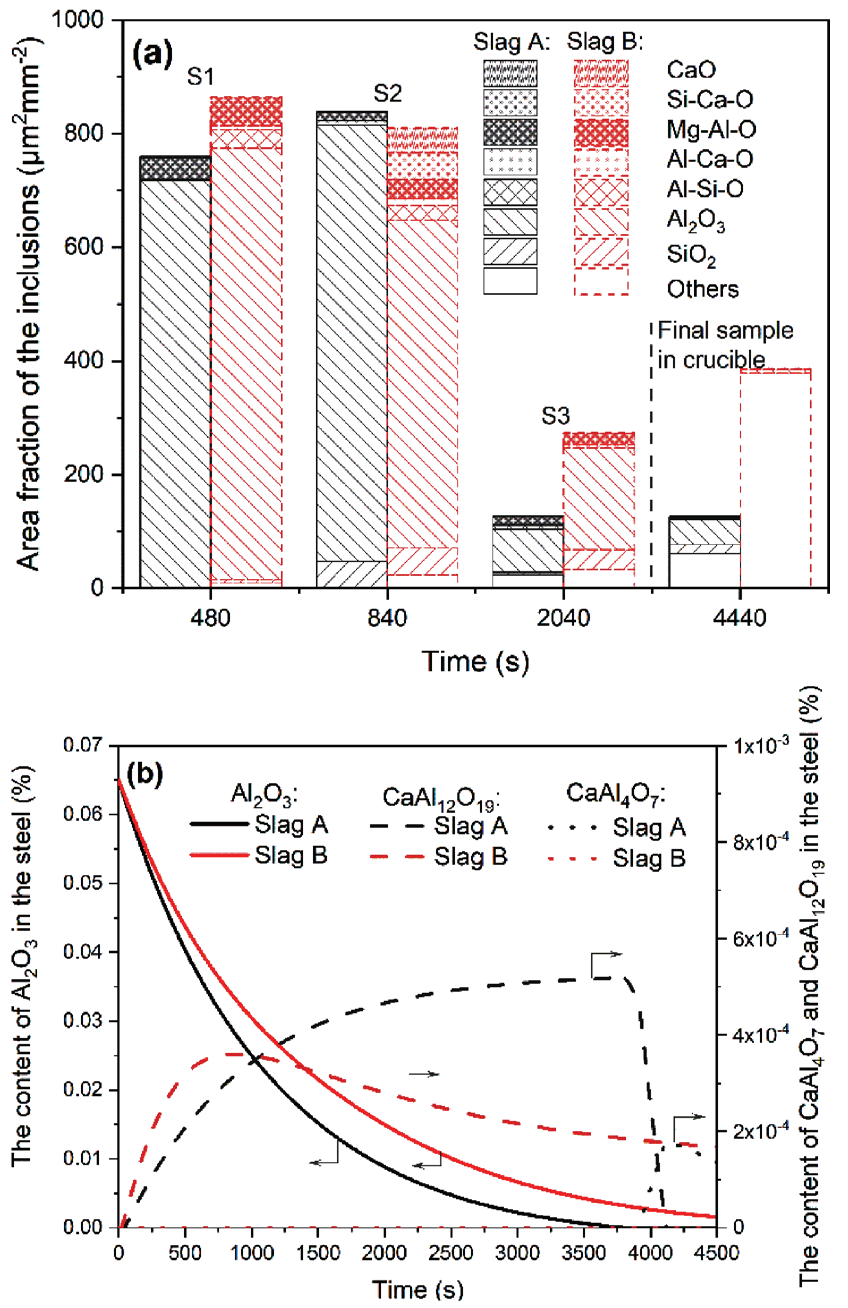

Fig. 4. The (a) measured area fraction and (b) calculated mass percentage of different-type inclusions during the experimental process. (Online version in color.)

type, while the sample from the experiment with slag A has a larger $\mathrm{Al}_{2} \mathrm{O}_{3}$ area fraction. The area fraction of other inclusions increases more in the case of slag $\mathrm{B}$ than that in the case of slag A. From $840 \mathrm{~s}$ (S2) to $2040 \mathrm{~s}$ (S3), the total area fraction and $\mathrm{Al}_{2} \mathrm{O}_{3}$ area fraction significantly decrease by larger than $65 \%$. The area fraction of other oxides also decreases to some extent. The total area fraction of the inclusions in the sample from the experiment with slag B is more than twice of that from the experiment with slag $\mathrm{A}$ after $2040 \mathrm{~s}$. In general, the total area fraction of the inclusions in the process samples ( $\mathrm{S} 1$ to $\mathrm{S} 3$ ) contacting with slags $\mathrm{A}$ and $\mathrm{B}$ show a similar trend. The $\mathrm{Al}_{2} \mathrm{O}_{3}$ area fraction significantly decreases after $840 \mathrm{~s}$. The area fractions of oxide compounds fluctuate in a small scale, which results from the balance of inclusion removal and modification.

The inclusion area fractions in the final steel sample (from the crucible) are also displayed in Fig. 4(a), though it is not wholly comparable to the process samples (S1 to S3) due to the different sampling conditions. As shown in Fig. 4(a), the dominant inclusion type changes from $\mathrm{Al}_{2} \mathrm{O}_{3}$ to the type 'Others' in both experiments. Note that also the steel/slag interface of remaining regulus in the crucible was analyzed. The limited total inclusion and pure $\mathrm{Al}_{2} \mathrm{O}_{3}$ area fractions indicate that most inclusion can pass through the steel/slag interface in the present experiments.
In Fig. 4(b), $\mathrm{Al}_{2} \mathrm{O}_{3}$ is the dominant inclusion type almost in the whole experimental process and its mass percentage is in a decreasing trend, which is similar to the measurements. Note that the predicted $\mathrm{Al}_{2} \mathrm{O}_{3}$ mass percentage in the case of slag A is decreased to zero after $3700 \mathrm{~s}$ is unrealistic. There is limited mass percentage of $\mathrm{CaAl}_{12} \mathrm{O}_{19}$ and $\mathrm{CaAl}_{4} \mathrm{O}_{7}$. The total inclusion content will be further analyzed and discussed in the following.

Figure 5 displays the concentration of the predicted and measured $\mathrm{Si}$ and $\mathrm{Al}$ and the predicted $\mathrm{Mn}$ during the experimental process. Note that the percentage $(\%)$ in the present work stands for weight percent. Table 3 lists fitted mass transfer coefficients based on the concentrations of $\mathrm{Al}$ and $\mathrm{Si}$ and inclusions removal rates as derived from the inclusion content. The values are in a reasonable range, compared to the reported values for the laboratory experiments. ${ }^{35,36}$ ) Figure 6 shows the changes of the predicted slag compositions. From Fig. 5(a), it is found that the calculated Si and Al concentrations agree well with the final measured value using the fitting parameters. Figure 5(b) displays only the calculated Mn concentration. The measured Mn concentration is not comparable to the prediction due to the Mn increase from the sampling tube. During the experimental process, $\mathrm{Si}$ concentration in the steel increases due to $\mathrm{Al}$ and $\mathrm{Mn}$ in the steel reduction the $\mathrm{SiO}_{2}$ in the slag (Fig. 6(b)), which leads to the decreased $\mathrm{Al}$ and $\mathrm{Mn}$ concentrations in the steel (Fig. 5). As shown in Fig. 6, the $\mathrm{Al}_{2} \mathrm{O}_{3}$ content in the slags gradually increases due to steel/slag reaction and inclusion removal, and $\mathrm{SiO}_{2}$ content gradually decreases. From Fig. 5(a), the concentration of $\mathrm{Si}$ in the experiment with slag $\mathrm{A}$ is higher than that with slag $\mathrm{B}$. This is due to more reduction of $\mathrm{SiO}_{2}$ in the slag by $\mathrm{Mn}$ in the steel (Figs. 5(b) and 6) under the similar Al concentrations (the difference is within $10 \mathrm{ppm}$ ). As a result, the $\mathrm{MnO}$ content in slag $\mathrm{B}$ is higher than that of slag A (Fig. 6(b)). The concentration difference of $\mathrm{Si}$ in the experiments of slags A and B is within 45 ppm, even though the fitted mass transfer coefficient in the case of slag A is 14 times higher than that in the case of slag B. This is can be explained by that the activity of $\mathrm{SiO}_{2}$ in the slag B: FactSage calculations result in a $\mathrm{SiO}_{2}$-activity of 0.04 in slag $\mathrm{B}$ and only 0.008 in slag A. The smaller mass transfer coefficient in the case of slag B is due to the higher viscosity (Table 2) and solid precipitations, as illustrated by the former study. ${ }^{37}$ As given in Eq. (4), the mass transfer coefficient is inversely proportional to the slag viscosity. The slag viscosity is significantly increased by the solid phase in the liquid slag, as given in Eq. (5), which results in a lower diffusion coefficient of the components in the slag. ${ }^{38)}$ Figure 7 shows the microstructure of the quenched slags. It is found that slag A (Fig. 7(a)) shows some dendrite structures due to the solidification, while the composition differences inside the dendrites and between the dendrites are only marginal. In contrast, slag $\mathrm{B}$ contains a number of solid $\mathrm{Al}_{2} \mathrm{O}_{3}$ (with the dark gray color in Fig. 7(b)) as 'island' in the liquid slag. The solid $\mathrm{Al}_{2} \mathrm{O}_{3}$ is believed to result from removed but not dissolved inclusions from the steel because of the high $\mathrm{Al}_{2} \mathrm{O}_{3}$ activity in slag $\mathrm{B}$ (approximately 0.9), which decreases the mass transfer. Note that the formation of solid precipitations during solidification is limited due to the rapid quenching. It is believed that slag $\mathrm{A}$ is completely liquid and slag $\mathrm{B}$ is liquid with solid $\mathrm{Al}_{2} \mathrm{O}_{3}$ phase at $1600^{\circ} \mathrm{C}$. The viscosity of slag $\mathrm{B}$ (with solid phase) 

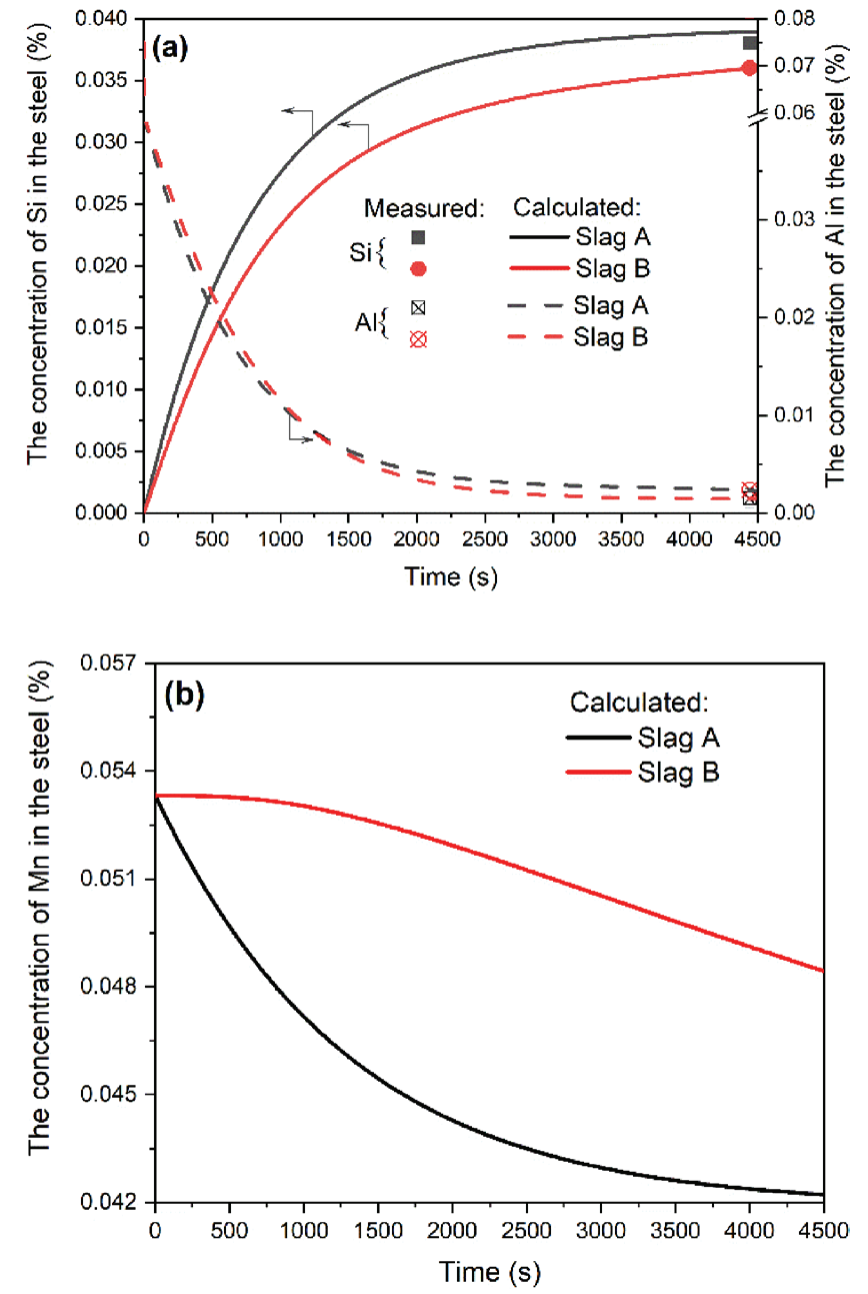

Fig. 5. The concentration of (a) the calculated and measured $\mathrm{Si}$ and $\mathrm{Al}$ and (b) the calculated Mns during the experimental process. (Online version in color.)

Table 3. The fitting parameters for the simulation of the experiments.

\begin{tabular}{cccc}
\hline Parameters & $\begin{array}{c}\text { Mass transfer } \\
\text { coefficient of steel } \\
\left(k_{s t}, \times 10^{-5} \mathrm{~ms}^{-1}\right)\end{array}$ & $\begin{array}{c}\text { Mass transfer } \\
\text { coefficient of slag } \\
\left(k_{s l}, \times 10^{-6} \mathrm{~ms}^{-1}\right)\end{array}$ & $\begin{array}{c}\text { Inclusion removal } \\
\text { rate }\left(r_{r e}, \times 10^{-3} \mathrm{~s}^{-1}\right)\end{array}$ \\
\hline Slag A & 3.5 & 3.5 & 1.0 \\
Slag B & 3.5 & 0.25 & 0.8 \\
\hline
\end{tabular}

was inversely calculated by Eq. (4) through comparing the mass transfer coefficient of slag A and B (Table 3 ) and the given viscosity of slag A in Table $2\left(0.393 \mathrm{Pas}^{-1}\right)$. Further the volume fraction of solid phase in slag B was inversely estimated by Eq. (5) using the former calculated viscosity (with solid phase, 77.03 $\mathrm{Pas}^{-1}$ ) and the given viscosity of the liquid slag B $\left(0.76 \mathrm{Pas}^{-1}\right)$. The estimated volume fraction of the solid precipitation in slag B is approximately 0.62 , which is close to that shown in Fig. 7(b) (0.48 of area fraction). The Si concentration change also indicates that the steel/slag reaction is controlled by mass transfer as well as slag composition.

$$
\begin{gathered}
k_{s l} \propto \eta^{-0.5} \ldots \ldots \\
\eta=\frac{\eta_{0}}{(1-1.35 f)^{2.5}}
\end{gathered}
$$
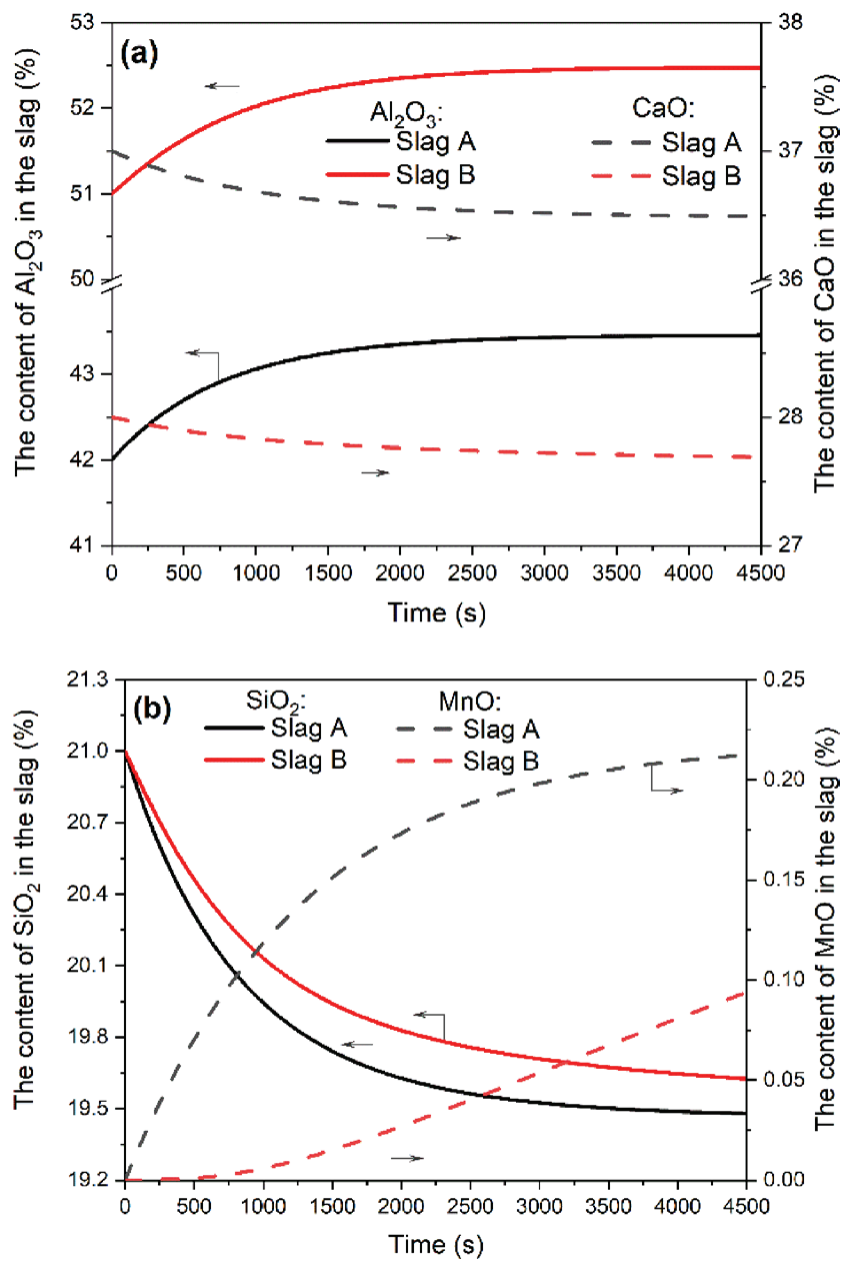

Fig. 6. The calculated slag compositions (a) $\mathrm{Al}_{2} \mathrm{O}_{3}$ and $\mathrm{CaO}$ and (b) $\mathrm{SiO}_{2}$ and $\mathrm{MnO}$. (Online version in color.)

where $k_{s l}$ is the mass transfer coefficient of slag, $\eta$ is the viscosity of slag, $\eta_{0}$ is the viscosity of the liquid slag, $f$ is the volume fraction of the solid phase in slag. Figure 8 shows the calculated and measured total inclusion content during the experimental process. Note that the measured inclusion mass percentage in Fig. 7 is calculated from the measured area fraction assuming equality of area fraction and volume fraction. The calculated and measured inclusion contents may be considered to be consistent in view of their time evolution, which illustrates the reasonability of the simulations. The evolution trend of the inclusion-content in the case of experiments with slag A and B are similar. The initial inclusion content is calculated based on the thermodynamic equilibrium of $\mathrm{Al}$ and $\mathrm{O}$ in the steel. Then the calculated inclusion content gradually decreases in the whole process due to the simple consideration of a constant removal rate. The inclusion content before $\mathrm{Al}$ addition is marginal due to the melting and homogenization process. Hence the measured content was assumed as zero, initially. The discrepancy of the measurements and calculations before $480 \mathrm{~s}$ is attributed to the thermodynamic essence of the inclusion calculation. The measured inclusion content changes little from 480 to $840 \mathrm{~s}$. During this period, the removal of inclusions may be a sort of dynamic equilibrium with the formation of new inclusions due to reduction of $\mathrm{SiO}_{2}$ from the slag by $\mathrm{Al}$ in the steel. Undissolved $\mathrm{Al}_{2} \mathrm{O}_{3}$ in the slag may also return to the steel. Note that the sampling process can cause steel stirring 
and inclusion transfer even though there is no stirring step and heating stirring. The concentration decrease rate of Al in Fig. 5 indicates the fast reaction and inclusion generation. The discrepancy of the measured and calculated inclusion content by $840 \mathrm{~s}$ is explained by the ignorance of inclusion back transfer to steel and inclusion formation due to steel/ slag reaction. The measured inclusion content significantly decreases from $840 \mathrm{~s}$ to $2040 \mathrm{~s}$. This is attributed to the larger removal rate compared with newly generated inclusions. In this period, the inclusion generation from steel/slag reaction significantly decreases due to the former $\mathrm{Al}$ consumption, which is indicated by the concentration change in Fig. 5. After $2040 \mathrm{~s}$, it is believed that the inclusion content shows only limited changes due to the limited and similar removal and generation amount. Based on the discussed mechanisms of inclusion removal and inclusion generation, the experimental can be classified into four periods (I to IV) as summarized in Table $\mathbf{4}$ and displayed in Fig. 8. It is concluded, that the inclusion content is determined by the balance of inclusion removal and generation.

As shown in Fig. 8, the inclusion content in the experiment with slag B is larger than that in the experiment with slag A. This is explained by the aforementioned balance of inclusion removal and generation. One further possible reason is that the lower driving force for the inclusion dissolution besides the higher viscosity in slag B lead to the longer dissolution time and even the limited dissolution. This further reduces the inclusion removal rate as indicated in Eq. (6). ${ }^{2,3,22)}$ A longer dissolution time and a limited dissolution may possibly result in the return transport of inclusion into the steel. Another possible reason is the generation of the inclusions in the steel after steel/slag reaction in the case of slag B. This means that more formed inclusions remain in the steel after $\mathrm{Al}$ in the steel oxidized by slag $\mathrm{B}$ compared to the case of slag A, which is due to the high viscosity of slag B. Further experiments are necessary to clarify the mechanisms.

$$
\log (r) \propto \log \left(\frac{1}{\tau}\right) \propto \log \left(\frac{\Delta C}{\eta}\right)
$$

where $r$ is the inclusion removal rate, $\tau$ is the inclusion dissolution time, $\Delta C$ is the mass fraction difference of the component in slag and inclusion, $\eta$ is the viscosity of slag.

The present work is the first step in the research group to

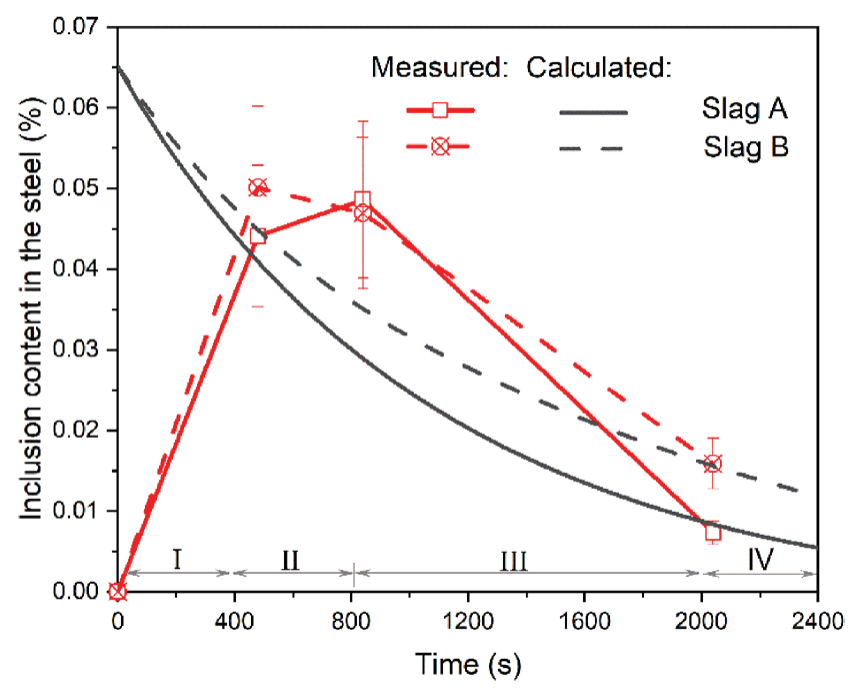

Fig. 8. The calculated and measured inclusion content changes during the experimental process. (Online version in color.)

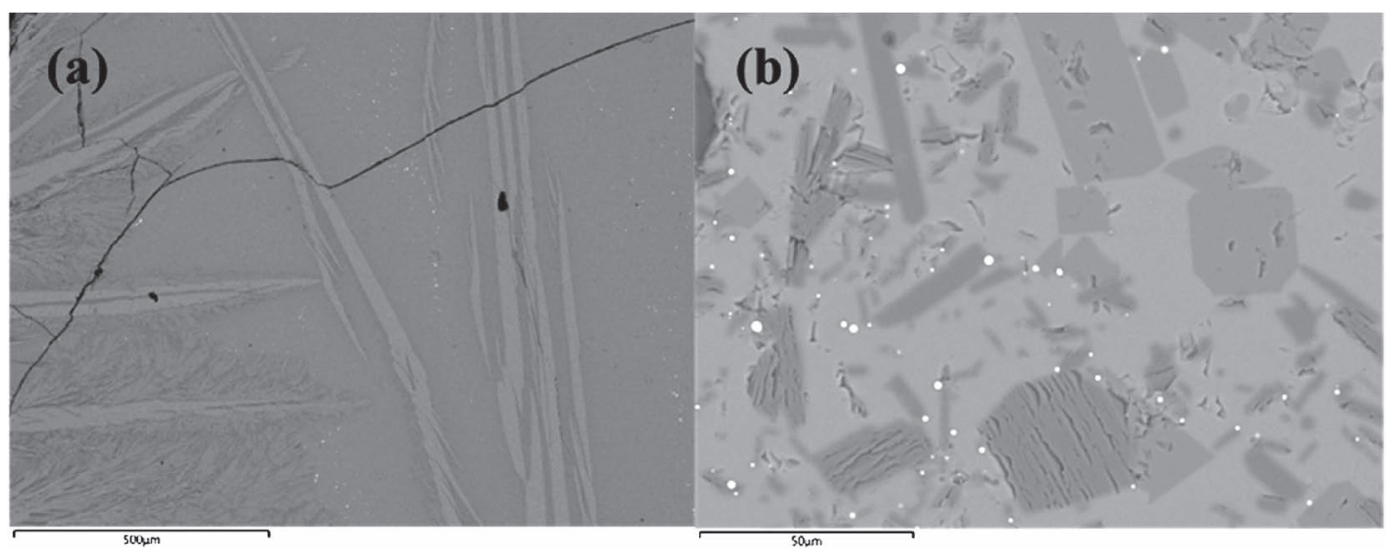

Fig. 7. Microstructure of (a) slag A and (b) slag B from the quenching samples.

Table 4. The assumed inclusion content evolution periods in the steel.

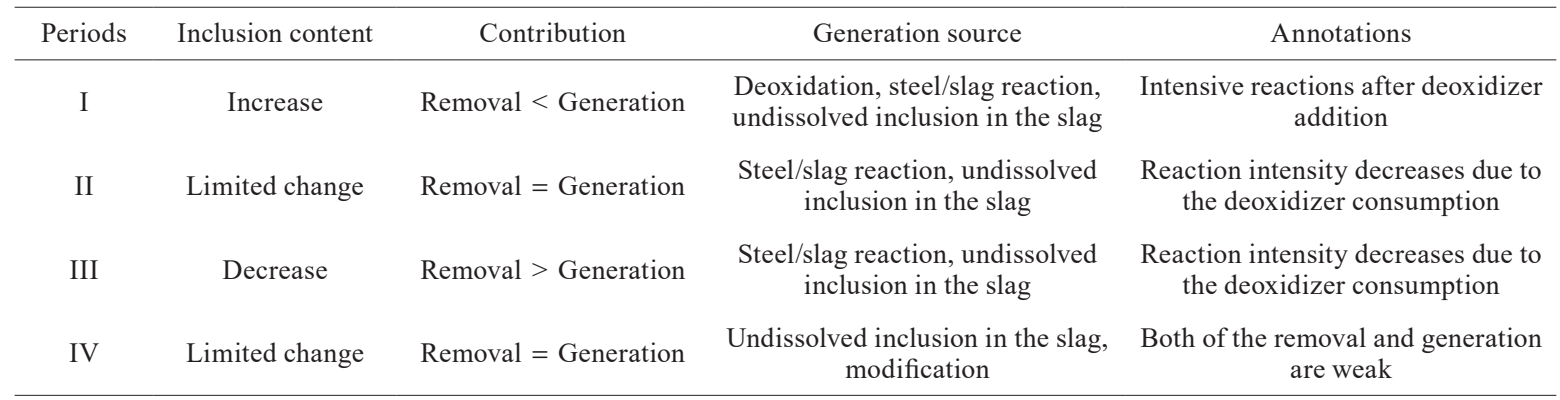


explore the mechanism of inclusion removal and inclusion content changes in steel. The results suggest that the inclusion back-transport from the steel/slag interface and slag side which strongly influences the inclusion content, should be accounted for. From the viewpoints of the authors, the inclusion removal mechanism is as following: (1) floating to the interface; (2) separation; (3) dissolution; (4) backtransport from the interface and/or slag side. The inclusion removal process is closely related to the steel fluid flow, stirring intensity, inclusion size and composition, slag viscosity and composition and interfacial properties. The inclusion removal was simplified to a rate parameter in the present simulation which will be necessarily improved. It is ideally to consider the aforementioned aspects as possible in the future modeling work. Then it may be helpful to understand and explain the practical steelmaking phenomenon, e.g. reoxidation by slag and the better effects of soft bubbling at the late stage of refining. The computational fluid dynamics including particles combined with chemical reactions is challenging for both modeling and application. The simple empirical equation considering stirring, slag viscosity and interfacial properties is a potential approach to the better simulation. The kinetic model of the interfacial reaction should be also reconstructed to consider the inclusion formation and back-transport.

\section{Summary}

The laboratory experiments and a corresponding thermodynamic simulations were performed to study the influence of slag composition and viscosity on the inclusion removal from the steel after deoxidation with Al. Based on the results, it is summarized that:

- The slag composition and viscosity have a significant influence on the inclusion content in the steel.

- The inclusion generation and removal determine the evolution of the inclusion content during the experiment. The steel/slag reaction and possible back-transport of undissolved inclusions due to sampling practice can be the source of the formation of new inclusions in the steel.

- The longer dissolution time or limited dissolution of inclusion in the slag can increase the possibility of inclusion back-transport into the steel and also decrease the removal rate.

- The slag viscosity effects on the mass transfer and the steel/slag reaction is controlled by both the mass transfer and activities.

Further experiments will be performed to clarify and confirm the mechanism of inclusion removal and generation and to include the role of well controlled forced convection in the system. In future modeling work, it is necessary to consider the influence of slag properties on the primary parameters, e.g. mass transfer coefficient and inclusion removal rate.

\section{Acknowledgement}

The authors gratefully acknowledge the funding support of K1-MET GmbH, metallurgical competence centre. The research program of the competence centre K1-MET is supported by COMET (Competence Centre for Excellent Technologies), the Austrian program for competence centres. COMET is funded by the Federal Ministry for Transport, Innovation and Technology, the Federal Ministry for Digital and Economic Affairs, the province of Upper Austria, Tyrol, and Styria, the Styrian Business Promotion Agency. A partial financing comes from scientific and the industrial partners: voestalpine Stahl, voestalpine Stahl Donawitz, Primetals Technologies Austria and RHI Magnesita.

\section{REFERENCES}

1) S. H. Lee, C. Tse, K. W. Yi, P. Misra, V. Chevrier, C. Orrling, S. Sridhar and A. W. Cramb: J. Non-Cryst. Solids, 282 (2001), 41.

2) M. Valdez, G. S. Shannon and S. Sridhar: ISIJ Int., 46 (2006), 450.

3) B. H. Reis, W. V. Bielefeldt and A. C. F. Vilela: ISIJ Int., 54 (2014), 1584.

4) B. H. Reis, W. V. Bielefeldt and A. C. F. Vilela: J. Mater. Res. Technol., 3 (2014), 179.

5) B. A. Webler and P. C. Pistorius: Metall. Mater. Trans. B, 51 (2020), 2437.

6) D. Bouris and G. Bergeles: Metall. Mater. Trans. B, 29 (1998), 641.

7) K. Nakajima and K. Okamura: Proc. 4th Int. Conf. on Molten Slags and Fluxes, ISIJ, Tokyo, (1992), 505.

8) C. Liu, S. Yang, J. Li, L. Zhu and X. Li: Metall. Mater. Trans. B, 47 (2016), 1882.

9) S. Yang, J. Li, C. Liu, L. Sun and H. Yang: Metall. Mater. Trans. B, 45 (2014), 2453.

10) J. Strandh, K. Nakajima, R. Eriksson and P. Jönsson: ISIJ Int., 45 (2005), 1597.

11) J. Strandh, K. Nakajima, R. Eriksson and P. Jönsson: ISIJ Int., 45 (2005), 1838.

12) S. Sridhar and A. W. Cramb: Metall. Mater. Trans. B, 31 (2000), 406.

13) M. Valdez, K. Prapakorn, A. W. Cramb and S. Seetharaman: Steel Res., 72 (2001), 291.

14) A. B. Fox, M. E. Valdez, J. Gisby, R. C. Atwood, P. D. Lee and S. Sridhar: ISIJ Int., 44 (2004), 836.

15) B. Monaghan and L. Chen: J. Non-Cryst. Solids, 347 (2004), 254.

16) J. Liu, F. Verhaeghe, M. Guo, B. Blanpain and P. Wollants: J. Am. Ceram. Soc., 90 (2007), 3818.

17) S. Michelic, J. Goriupp, S. Feichtinger, Y.-B. Kang, C. Bernhard and J. Schenk: Steel Res. Int., 87 (2016), 57.

18) M. Söder, P. Jönsson and L. Jonsson: Steel Res. Int., 75 (2004), 128.

19) L. Wang, Q. Zhang, S. Peng and Z. Li: ISIJ Int., 45 (2005), 331.

$20)$ D. Sheng, M. Söder, P. Jönsson and L. Jonsson: Scand. J. Metall., 31 (2002), 134

21) M. Hallberg, P. G. Jönsson, T. L. I. Jonsson and R. Eriksson: Scand. J. Metall., 34 (2005), 41.

22) J. Park and J. Park: Metall. Mater. Trans. B, 47 (2016), 3225.

$23)$ Z. Liu, G. Song, Z. Deng and M. Zhu: Metall. Mater. Trans. B, 52 (2021), 1243.

24) J. Shin and J. Park: Metall. Mater. Trans. B, 51 (2020), 1211.

25) C. Liu, X. Gao, S. Ueda and S. Kitamura: ISIJ Int., 59 (2019), 268.

26) C. Liu, X. Gao, S. Ueda, M. Guo and S. Kitamura: ISIJ Int., 60 (2020), 1835.

27) W.-Y. Kim, G.-J. Nam and S.-Y. Kim: Metall. Mater. Trans. B, 52 (2021), 1508.

28) M. van Ende, Y. Kim, M. Cho, J. Choi and I. Jung: Metall. Mater. Trans. B, 42 (2011), 477.

29) P. Dorrer, S. K. Michelic, C. Bernhard, A. Penz and R. Rössler: Steel Res. Int., 90 (2019), 1800635.

30) M. Van Ende and I. Jung: Metall. Mater. Trans. B, 48 (2017), 28.

31) S. P. T. Piva, D. Kumar and P. C. Pistorius: Metall. Mater. Trans. B, 48 (2017), 37.

32) J. H. Shin, Y. Chung and J. H. Park: Metall. Mater. Trans. B, 48 (2017), 46.

33) D. You, C. Bernhard, P. Mayer, J. Fasching, G. Kloesch, R. Rössler and R. Ammer: Metall. Mater. Trans. B, 52 (2021), 1854.

34) S. Petersen and K. Hack: Int. J. Mater. Res., 98 (2007), 935.

35) D. Kumar and P. C. Pistorius: Metall. Mater. Trans. B, 50 (2019), 181.

36) J. Park and L. Zhang: Metall. Mater. Trans. B, 51 (2020), 2453.

37) D. J. Kim and J. H. Park: Metall. Mater. Trans. B, 43 (2012), 875.

38) R. Roscoe: Br. J. Appl. Phys., 3 (1952), 267. 